University of Nebraska - Lincoln

DigitalCommons@University of Nebraska - Lincoln

2000

Stochastic Variation in Food Availability Influences Weight and Age at Maturity

Brigitte Tenhumberg

University of Nebraska - Lincoln, btenhumberg2@unl.edu

Andrew J. Tyre

University of Nebraska at Lincoln, atyre2@unl.edu

Bernie Roitberg

Simon Fraser University, roitberg@sfu.ca

Follow this and additional works at: https://digitalcommons.unl.edu/bioscifacpub

Part of the Life Sciences Commons

Tenhumberg, Brigitte; Tyre, Andrew J.; and Roitberg, Bernie, "Stochastic Variation in Food Availability Influences Weight and Age at Maturity" (2000). Faculty Publications in the Biological Sciences. 121.

https://digitalcommons.unl.edu/bioscifacpub/121

This Article is brought to you for free and open access by the Papers in the Biological Sciences at DigitalCommons@University of Nebraska - Lincoln. It has been accepted for inclusion in Faculty Publications in the Biological Sciences by an authorized administrator of DigitalCommons@University of Nebraska - Lincoln. 


\title{
Stochastic Variation in Food Availability Influences Weight and Age at Maturity
}

\author{
Brigitte Tenhumberg, Andrew J. Tyre, and Bernie Roitberg \\ Behavioral Ecology Research Group, Department of Biological Sciences, \\ Simon Fraser University, Burnaby, BC, Canada V5A 1 S6 \\ Corresponding author - B. Tenhumberg. \\ Present address: University of Nebraska-Lincoln, email btenhumberg2@unl.edu
}

\begin{abstract}
Variation in mean food availability, and in the variance around the mean, affects the growth rate during development. Previous theoretical work on the influence of environmental quality or growth rates on the phenotypic traits age and size at maturation assumed that there is no variation in growth rate or food availability within a generation. We develop a stochastic dynamic programming (SDP) model of the foraging behavior of aphidophagous syrphids, and use this model to predict when syrphids should pupate (mature) when average food availability changes, or varies stochastically, during development. The optimal strategy takes into account not only the availability of food, but also the timing of its availability. Food availability, when small, influences developmental time, but not weight at pupation. Food availability, when large, influences weight at pupation, but not developmental time. When the food supply is low, the optimal strategy adjusts the size at pupation downwards for stochastic as opposed to deterministic availability of food. The conclusions reinforce the need for lifehistory studies to consider state dependence and short-term variability in growth rates.
\end{abstract}

\section{Introduction}

The two most important determinants of fitness and population growth are the age and size of an organism at maturity. As a consequence, these two determinants have been the focus of intense empirical and theoretical investigation (reviewed in Roff, 1992; Stearns, 1992; see also Charlesworth, 1994) since Cole (1954) first described how they influenced population growth. The intent of most theoretical work has been to predict how these deter- minants change in response to changes in growth rate (Stearns \& Koella, 1986; Charnov, 1989; Berrigan \& Koella, 1994), temperature (Berrigan \& Charnov, 1994), juvenile mortality (Hernandez \& León, 1995; Abrams et al., 1996), predation risk (Abrams \& Rowe, 1996), or seasonal limitations (Roff, 1983; Rowe \& Ludwig, 1991). With one exception (Bull et al., 1996), none of these models examined the effect of short-term variation in food availability on life-history traits, or risk sensitivity (Real \& Caraco, 1986). We address this question by developing 
a stochastic dynamic programming (Bellman, 1957; Mangel \& Clark, 1988) model of a specific species, the syrphid fly Episyrphus balteatus.

Growth rate depends directly on foraging effort, and so optimal foraging behavior necessarily influences age and size at maturity. The consequences of flexible "growth effort" for age and size at maturity have been well described in general models (Abrams et al., 1996; Abrams \& Rowe, 1996) under conditions of constant food availability. However, foraging behavior is also sensitive to the variance of food availability (Real \& Caraco, 1986). Therefore, variation in food availability will affect life-history strategies.

Ludwig \& Rowe (1990) and Rowe \& Ludwig (1991) allowed growth rates to differ between two habitats in their deterministic dynamic programming models of ontogenetic niche shifts. Organisms switch between two habitats to maximize fitness by tradingoff reduced growth against a decreased mortality risk in the safer habitat. When the density of individuals in a particular habitat influences their risk of mortality from predation this habitat switch is a state-dependent game (Bouskila et al., 1998). However, many other consumers experience short-term variability in food availability, and hence growth rate, that cannot be avoided by switching to a different habitat. For these consumers the only way to trade-off growth against mortality is to adjust the duration of their development. Consumers that develop for shorter periods reduce overall mortality risk, but at the cost of decreasing their fitness payoffs when fitness is related to size.

Food availability varies on both long and short time-scales. First, average food availability can change in response to some other environmental trend at time-scales that are long relative to individual foraging decisions. Prey populations in many systems oscillate with the seasons, or with changes in their food availability. Food availability also varies on time-scales the same or shorter than the timescale of individual foraging decisions. The number of prey encountered by a predator during a particular period of time is a random variate with a mean and variance. The predator can use the actual number of prey encountered to estimate current food availability at short time-scales, but these estimates need to be flexible to allow for variation at longer times- cales. Risk sensitivity, or responses to changes in the variance of foraging options, has been experimentally demonstrated for bees (Harder \& Real, 1987; Cartar, 1991), and birds (Barkan, 1990). These studies generally consider switching between two foraging "patches" with differing variances and similar average food available. As already discussed, there may be consumers who do not have a choice of patches (e.g. juvenile salmon; Bull et al., 1996). Our model examines the possibility that such organisms respond to variable foraging environments by adjusting their developmental trajectory.

Age and size at maturity are phenotypic traits, and food availability is an environmental variable. Plotting the value of a phenotypic trait against an environmental variable creates a "norm of reaction" (Stearns, 1992), and is a useful way of visualizing the effect of environmental variation on phenotypic characters (e.g. Dingle, 1992). Environmentally induced differences in phenotypes, within a genotype, are shifts along a single norm of reaction. Differences between genotypes are represented by different reaction norms (Stearns \& Koella, 1986; Berrigan \& Koella, 1994). Our model predicts the shape of reaction norms for size and age at maturity as a function of food availability. We do not treat the relationship between size and age at maturity as a reaction norm (e.g. Stearns \& Koella, 1986)*age at maturity is not an environmental variable (Abrams et al., 1996). We plot size and age separately as functions of the environmental variable food availability.

Observed phenotypic variation in response to environmental variation could be an adaptive response to the environment and/or an inescapable reaction to the environment (Berrigan \& Koella, 1994). If the observed phenotypic response to environmental variation in food availability matches a predicted optimal response, then it is possible that the phenotypic response is adaptive. Without a predicted optimum it would be difficult to determine if a particular phenotypic response is due to constraints or adaptive.

In this paper, we construct a stochastic dynamic programming (SDP) model of how changes in the average and variance of food availability influence age and size at maturity. We have chosen to model the aphidophagous syrphid Episyrphus balteatus (Diptera: Syrphidae), because we have data on the func- 
tional response, growth rates, and developmental times. Syrphids are holometabolous insects which undergo a complete metamorphosis when entering the adult stage. Therefore, the age and size at maturity largely determine the time of and weight at pupation. For the remainder of this paper, we use age and weight at pupation as synonymous with age and size at maturity.

Episyrphus balteatus is a common aphid predator in cereal crops in central and western Europe (Tenhumberg \& Poehling, 1995). Adults forage for pollen and nectar. Adult females also search for aphid colonies which are the main oviposition sites. Eggs must be laid in or near an aphid colony, because newly hatched larvae have limited mobility and starve quickly. Larvae search for aphid colonies, and feed by sucking the contents of individual aphids. They grow for approximately 2 weeks, and then pupate. Adults either emerge after a few weeks, or overwinter as pupae, depending on timing of pupation. Adults emerging in the late summer or early fall may also choose to undergo a seasonal migration southwards, returning in the following spring. Late season individuals may also exploit aphid colonies on other plants after cereal crops ripen.

A specific model, rather than a general one, means that our assumptions can be grounded in data and observation, and provides the opportunity to test the predictions of the model quantitatively. The great variation in physiological constraints and ecological situation among organisms has led some biologists to plead for specific, testable models (Kozlowski, 1992; Ydenberg, 1994).

\section{Model Description}

SDP models find an optimal-state-dependent strategy that maximizes a fitness currency. The model computes the fitness currency at each state at a final time horizon. The model then steps back by one time period and computes the fitness associated with each behavior from the set of possible behaviors for each combination of internal states. Each behavior causes the internal states to change in a particular way. The optimal behavioral choice for a particular state and time has the highest value for the fitness currency.
Our SDP model calculates the optimal behavior of a larva that estimates average food availability from past foraging success. The optimal decisions are stored in a matrix indexed by time, weight, gut content and memory state. We use forward MonteCarlo simulations to translate the optimal individual behavior into expected developmental times, pupal weights and mortality. In the simulation, the average food availability, $\varphi$, is a parameter that can be adjusted to examine the effect of changes in average food availability during development. To examine the influence that stochastic variability has, we set $A$, the number of aphids captured in a time step, to either a negative binomial distributed random variable, or exactly equal to $\varphi$. In the results we refer to negative binomial distributed $A$ as a "random food schedule", while a constant $A$ is a "constant food schedule". It is important to remember that the SDP calculates optimal decisions under the assumption that food supply is randomly distributed. The constant-food-schedule simulations predict what larvae optimized in a fluctuating environment will do in a constant environment, as is commonly used in laboratory experiments. We simulated 500 larvae for each combination of parameters. Each larva experiences its own sequence of success rates, and the breakdown of the aphid population occurs randomly for each larva according to the conditional distribution discussed above.

One time step is $10 \mathrm{~h}$. This value represents a compromise between a higher resolution offered by smaller time steps, and the necessity of keeping the state/time space to a reasonable size. The parameters of the model and their numerical values are listed in Table 1.

\section{Physiological States and Dynamics}

We use two physiological states, weight, $w$, and gut content, $g$ :

$$
\begin{aligned}
& w \in\left[0, w_{\max }\right], \\
& g \in\left[g_{c r i t^{\prime}} g_{\max }\right] .
\end{aligned}
$$

$w_{\max }$ is the weight of the largest observed larva (Tenhumberg, 1992). $g_{\max }$ the maximum gut content for different sizes of larvae is a concave function of larval 
Table 1. List of all the parameters in the model and their numerical values

\begin{tabular}{lll}
\hline $\begin{array}{l}\text { Parameter } \\
\text { name }\end{array}$ & Description & Value \\
\hline$w_{\max }$ & Maximum weight of larvae & $40 \mathrm{mg}$ \\
$C_{M+W}$ & Proportion of gut content for growth and maintenance & 0.5 \\
$q$ & Proportion of assimilated aphids that convert to weight & 0.11 \\
$S$ & Starvation threshold & 0.1 \\
$r$ & Memory decay parameter & 0.5 \\
$\varphi, m$ & Average prey availability & Various \\
$k$ & Prey aggregation constant & 2 \\
$\rho$ & Probability of not being parasitized & 0.997 \\
$a$ & Maximum fitness & 350 \\
$b$ & Fitness threshold & 5.8 \\
$c$ & "Steepness" of fitness function & 8 \\
\hline
\end{tabular}

size (Tenhumberg, 1992; Figure 1). We assume that the initial increase in maximum consumption is due to a linear increase in gut size with body weight. The parameters for this linear function were estimated from a linear regression of the maximum number of aphids consumed on larval weight:

$$
g_{\max }=3.03 w+1.48 .
$$

We only use data points on the increasing side of the curve to estimate the parameters in Equation (3). We assume that the decline in maximum consumption at larger sizes occurs because the energy requirement for searching increases with larval weight as a 2/3 power law (Kooijman, 1993; see below), while the energetic gain from each prey unit is constant.

Changes in the physiological states are functions of metabolic costs and prey captures. The energetics of syrphid larvae are represented with a "metabolic pool" (Gutierrez et al., 1981). The contents of the pool are equivalent to gut content. The proportion of gut content used to meet growth and maintenance costs is $C_{M+W}$. We know the rate at which larvae gain weight when consuming a particular quantity of aphids (Tenhumberg, 1992), and so we can calculate the proportion $q$ of the utilized gut contents that get assimilated into weight. The remainder, $1-q$, is used to meet maintenance costs.

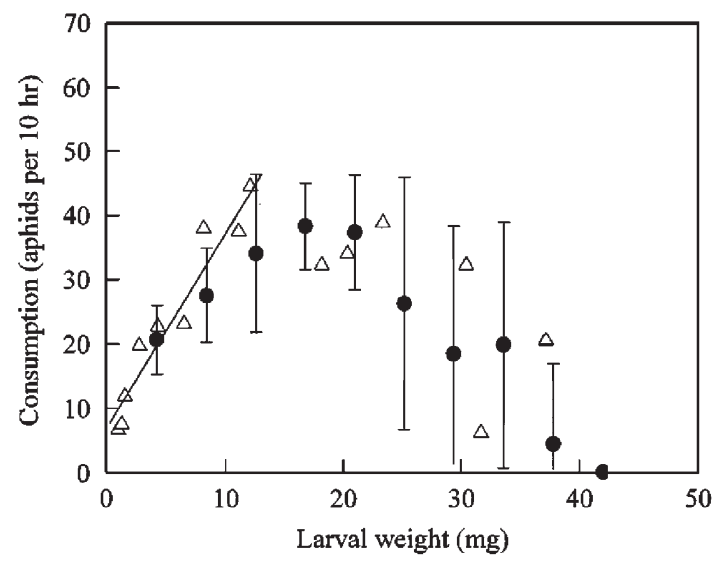

Figure 1. Number of aphids consumed in $10 \mathrm{hr}$ by both real (open triangles) and simulated (filled circles) syrphid larvae as a function of weight. The real data to the left of the arrow are used to generate the regression line $\left(r^{2}=0.92, p<0.01\right.$, solid line) estimating maximum gut content as a function of weight. Simulated syrphid points are the mean and standard error of 20 syrphids on a random food schedule. Both real and simulated syrphids were provided with excess food (> 36 aphids per $10 \mathrm{hr})$.

The simplification should only matter during periods of low food availability, when using the entire amount of assimilated gut contents for maintenance $(q=0)$ would make starvation less likely. Therefore, at low food availabilities, the mortality rate of model syrphids will be higher than that of real syrphids. 
Gut content is also decreased to pay the energetic costs of searching for prey, which are given by

$$
C_{s}=0.13 w^{2 / 3},
$$

where 0.13 is a general constant that applies to many species (Kooijman, 1993) and Cs is the cost of searching for aphids. This equation assumes that search costs are proportional to length squared (Kooijman, 1993), and that weight is proportional to the cube of length (Schmidt-Nielsen, 1984). Gut content increases when prey are captured, and we describe the encounter probabilities under the description of foraging behavior below. Individuals starve to death when the gut content at the end of a time step (i.e. after all reductions and increases in gut content) is less than $g_{\text {crit }}$ $=S g_{\text {max }}$, where $S$ is a fixed proportion.

\section{Information State and Dynamics}

In addition to the physiological states of weight and gut content, we assume that syrphids have a "memory state" $m$ that they use to estimate the current availability of food. Optimal foraging theory often assumes that animals are omniscient (Bell, 1991). This assumption can only hold when the environment changes in a completely predictable manner (Orians, 1981). It is likely that animals faced with uncertainty in food availability, such as syrphid larvae, estimate their future foraging success based on experience. Several studies have demonstrated that reasonable estimates can be provided by simple memory models (McNamara \& Houston, 1985, 1987a; Mangel \& Roitberg, 1989; Mangel, 1990; Li et al., 1993). Our memory state represents a weighted maximum likelihood estimate (MLE; Mangel, 1990) of the averaged food availability, where the syrphid repeatedly samples the environment by foraging, and incorporates that information into a new estimate. The influence of old information on the current estimate is assumed to decrease exponentially with time. The updating rule for the memory state is then

$$
m_{t+1}=r m_{t}+(1-r) A_{t},
$$

where $0<r<1$ is the decay rate for old information, and $A_{t}$ is the number of aphids encountered during time step $t$. The memory state ranges from
[0, 60] aphids per $10 \mathrm{hr}$. Newly hatched larvae usually have excess prey available, because syrphid females lay their eggs within or close to an aphid colony (Bastian, 1986). Therefore, in forward simulations we initialized the memory of newborn larvae $\left(m_{0}\right)$ with a relatively high value of 24 aphids per $10 \mathrm{hr}$.

Our memory model is a linear operator, which puts it in the same category as Kalman filters and other optimality methods for predicting future values of a time series from past information (Mangel, 1990). Kalman filters find an "optimal" combination of coefficients for predicting future values from past information. Incorporating this additional layer of optimization into an SDP model would radically increase the state space, making the model difficult or impossible to solve. Mangel (1990) explored learning rules for foragers in detail, and concluded that while "optimal forgetting rules" may exist, the optimum is likely to be broad, and selection therefore slow. We have chosen to concentrate on the consequences of information for the life-history problem, while reducing the solution to the information problem to Mangel's "sample and forget" rule. We will explore the fitness consequences of using our simple sampling rule vs. using no rule in the results below.

\section{Behavior Set and Fitness Values}

The model takes into account three alternative actions: "pupation," "resting," and "foraging." With the exception of pupation, each activity causes a change in weight and gut content as described above. Foraging larvae use energy for maintenance, convert gut content into body mass, spend energy to search for prey, find prey and run a risk of being parasitized. Resting larvae use up energy for maintenance, convert gut content into body mass and avoid parasitism. Both foraging and resting larvae risk starvation. A larva that pupates simply accumulates future fitness associated with its current weight.

The fitness value of foraging depends on the distribution of encounters with prey. Foragers catch $A$ prey units, where $A$ is negative binomial random variable with some mean $m$ and an aggregation index $k$ : 


$$
\begin{aligned}
p_{A} & =P\{A=a\} \\
& =\left[\frac{\Gamma(k+a)}{a ! \Gamma(k)}\right]\left(\frac{m}{m+k}\right)^{a}\left(\frac{k}{m+k}\right)^{k}
\end{aligned}
$$

where $\Gamma(k)$ is the gamma function (Krebs, 1989).

We set $k=2$, based on field observations of cereal aphid (Ohnesorge \& Viereck, 1983). This indicates a slightly aggregated distribution. In the SDP, the mean $m$ is just the current memory state of the syrphid. In the forward simulations, the average food availability is an external parameter $\varphi$ which can be varied; the memory state $m$ of a simulated individual still plays a role in determining which decision is taken.

In the case of syrphids, and other predators of annual crop pests, there is an additional source of uncertainty in food availability, beyond stochastic variation in prey capture rates. Harvesting or maturing of the crop often results in a catastrophic decline in prey populations. Aphid populations in fields of winter wheat can disappear rapidly in response to the ripening of their host plants. Syrphid larvae must complete larval development before the aphid population breaks down, otherwise they starve to death. The timing of the season end is influenced by both the maturation process of the aphid's host plant and the abundance of other aphid natural enemies. As these influencing factors are subject to yearly variation, the exact time of the aphid population breakdown is uncertain (Tenhumberg \& Poehling, 1995). In our model, we incorporated this uncertainty by computing the probability that the aphid season ended before time $t[S(T \leq t)]$, from population data in Tenhumberg (1992).

The overall payoff for searching incorporating both sources of variability in food availability is where $F(w, g, m, t, T)$ is the expected future fitness for weight $w$, gut content $g$, memory state $m$, at time $t$, and end of season T. If $g_{t+1}<g_{\text {crit }}$ the individuals starve and the expected future fitness is 0 . Once the prey population breaks down, the probability of encountering a prey is $0 . \rho$ is the probability of not being parasitized during the current time unit.

We assume that resting individuals do not experience a risk of parasitism, and only grow and lose gut content at metabolic costs. Many organisms avoid predation by resting in cryptic or concealed locations (Alcock, 1989). The payoff to resting is therefore

$$
\begin{aligned}
V_{\text {rest }}(w, g, m, t, T)= & F\left(w+\left(g C_{M+W} q\right),\right. \\
& \left.g\left(1-C_{M+W}\right), m, t+1, T\right) .
\end{aligned}
$$

The memory state $m$ of a resting larva does not change.

Larvae that pupate accumulate the expected future fitness that they would get by pupating at their current weight. We use the product of potential adult fitness and the probability of surviving to pupation as our fitness currency. This is comparable to $R_{0}$, the lifetime reproductive value of an organism (Roff, 1992). Other models have used $r$, the intrinsic rate of increase (Stearns \& Koella, 1986; Houston \& McNamara, 1992; Kawecki \& Stearns, 1993), $R_{0}$ (Berrigan \& Koella, 1994; Abrams \& Rowe, 1996; Nanacs et al., 1998 ) or something comparable to $R_{0}$ (Rowe \& Ludwig, 1991) as the optimization criterion when predicting the shape of reaction norms. The choice of fitness criterion qualitatively changes the outcome of the model, because using $r$ rewards individuals who achieve a shorter generation time (Roff, 1983). Syrphids have discrete generations, and $R_{0}$ is therefore adequate as a fitness criterion, assuming that there

$$
\left.V_{\text {search }}(w, g, m, t, T)=\rho \mid \begin{array}{l}
(1-S(T \leq t)) \sum_{A=0}^{A_{\max }}\left(p _ { A } F \left(w+\left(g C_{M+W} q\right)\right.\right. \\
\left.\left.g\left(1-C_{M+W}\right)-C_{S}+A, \gamma m_{t}+(1-\gamma) A, t+1, T\right)\right) \\
S(T \leq t) F\left(w+\left(g C_{M+W} q\right), g\left(1-C_{M+W}\right)-C_{S^{\prime}} r m_{t}, t+1, T\right)
\end{array}\right\}
$$




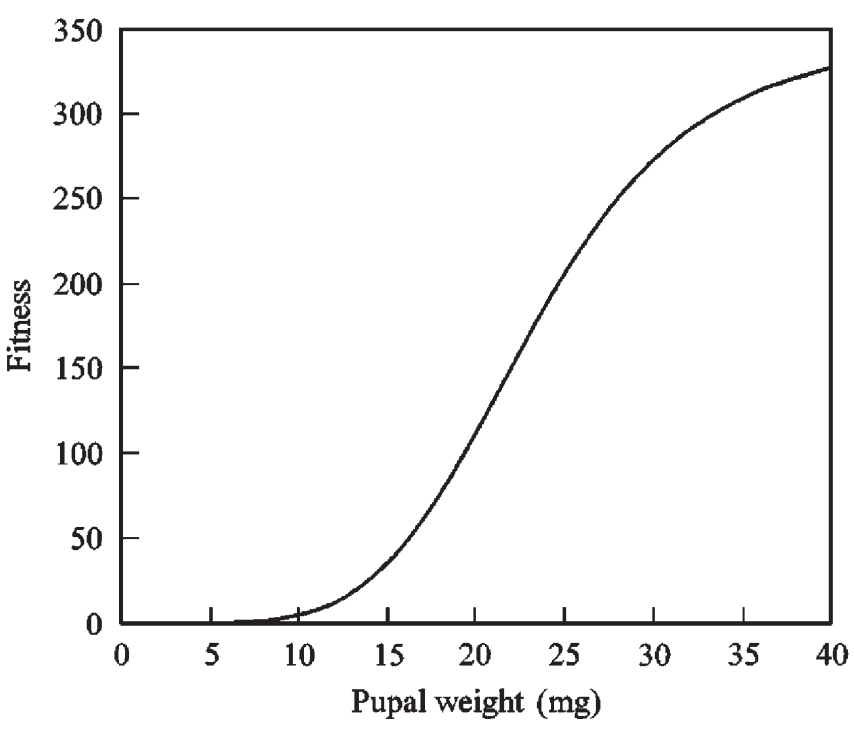

Figure 2. Relationship between pupal weight and fitness.

are a fixed number of generations per season (Roff, 1983). Alternatively, $R_{0}$ is acceptable if population size is stationary, i.e. $r=0$ (Charlesworth, 1994). Mangel et al. (1994) show how to extend the concept of lifetime reproductive success to include the effect of changes in offspring performance as a result of reproductive decisions made by the adult. We assume here that variation in weight at pupation affects fecundity (i.e. the number of offspring) but not the quality of those offspring. Mylius \& Diekmann (1995) demonstrated that maximizing $R_{0}$ gives an evolutionary stable strategy (i.e. resistance to invasion by mutants, Maynard-Smith, 1982) if density dependence acts to reduce life-time production of offspring. This is the case for syrphids, where high populations of larvae relative to the aphid population tend to lead to reduced sizes at pupation, and consequently, reduced adult fitness (Tenhumberg, 1992).

The relationship between size at maturity and adult fitness is positive for many organisms (Hinton, 1981; Thornhill \& Alcock, 1983; Mangel \& Clark, 1988; Roff, 1992; Colegrave, 1993). Syrphid fecundity, which is one component of fitness, is positively correlated with adult weight (Gaudchau, 1982), which is in turn correlated with weight at pupation (Tenhumberg, 1992). We expect that fitness will asymptote at large sizes, because no payoff can be unlimited (Mangel \& Clark, 1988; empirical examples in Ernesting et al., 1993; Speight, 1994; Heimpel et al., 1996). There should also be a threshold size below which it is not possible to mature. We assume a sigmoidal curve for the relationship between adult fitness and size at $\mathrm{pu}-$ pation (Figure 2):

$$
V_{\text {pupate }}(w)=\frac{a}{1+(b / w)^{c}}
$$

where $a$ is the asymptotic maximum fecundity, $b$ is related to the weight at which fitness begins to increase, and $c$ controls the rate at which fitness increases with weight.

The complete dynamic programming equation is then

$$
\begin{aligned}
F(w, g, m, t, T)=\underset{D}{\operatorname{MAX}}\left\{V_{\text {search }}(w, g, m, t, T),\right. \\
\left.\quad V_{\text {rest }}(w, g, m, t, T), V_{\text {pupate }}(w)\right\}
\end{aligned}
$$

where $\operatorname{MAX}_{D}$ is the operation of choosing the element of the decision set $D$ that gives the greatest payoff.

We checked our simplified energetic model by simulating syrphids with a superabundance of food, and comparing the maximum consumption with observations of real syrphids (Figure 1). This is not a "test" of the model, per se, as the model is being compared with the same data used to parameterize the gut constraint. However, the decrease in maximum feeding rate is not a constraint imposed by the data. Rather, it is an outcome of the optimal decision matrix produced by the SDP. Our interpretation of this change is that increasing energetic costs of searching leads to reduced foraging effort as larger sizes are achieved. It is reassuring to note that the output of the SDP is a decreasing consumption with body size of the same magnitude observed in real syrphids.

\section{Effect of Changes in Average Food Availability}

First, we examine the effects of changes in the average food availability within a single generation. Large larvae are more mobile and have larger gut capacity (relative to small larvae). Therefore, the foraging success of syrphid larvae depends on their size as well as on changes in prey abundance 
over time (Buggle, 1994), and the food availability may either increase or decrease as larvae grow larger. The influence of changes in $\varphi$ on developmental time and pupal weight may change with the size of the larvae. We incorporate this effect into the model by changing $\varphi$ as larvae grow from small $(<$ $12 \mathrm{mg}$ ) to large ( $\geq 12 \mathrm{mg})$, and observe the effects on developmental time and pupal weight. We set the boundary between small and large larvae to approximately half of the average weight of E. balteatus larvae found under high food availability in the field that are ready to pupate $(21\} 28 \mathrm{mg}$ depending on the year; Tenhumberg, 1992). We investigate only one combination of $\varphi$ for small $\left(\varphi_{\text {small }}\right)$ and large $\left(\varphi_{\text {large }}\right)$ larvae in a given run of the model. For example, larvae received an average of 12 aphids per $10 \mathrm{hr}$ until they grew to $12 \mathrm{mg}$ in weight, and then received an average of 25 aphids per $10 \mathrm{hr}$ until they pupated. We only consider food availabilities higher than 12 aphids per $10 \mathrm{hr}$, because the probability that a larva does not reach a weight of $12 \mathrm{mg}$ before pupating, and mortality from starvation both increase rapidly at lower levels of food availability. All runs use random food schedules.

We examine the relative fitness performance of our learning strategy against foragers that use a fixed estimate of food availability assuming $\varphi_{\text {small }}=$ $\varphi_{\text {large }}=24$ aphids per $10 \mathrm{hr}$. We calculate average fitness as the average of $V_{\text {pupate }}$ for individuals surviving to pupation, multiplied by the probability of surviving to pupation ( 1 - the proportion of simulated individuals dying before pupation). The average fitness of the memory-using strategy in a particular environment (characterized by a pair $\left\{\varphi_{\text {small }}, \varphi_{\text {large }}\right\}$ ) is divided by the average fitness achieved by the fixed estimate strategy in the same environment. We expect that the fixed estimate strategy will perform better than the learning strategy when the fixed estimate is in fact correct. The question is, how much worse is the learning strategy, and for what range of environments is the learning strategy better? We also compare the relative performance of the memory model with different values of $\gamma$ in a more realistic environment with aphid density varying continuously throughout the season. More extensive testing of the learning strategy's performance is beyond the scope of this paper. We are primarily

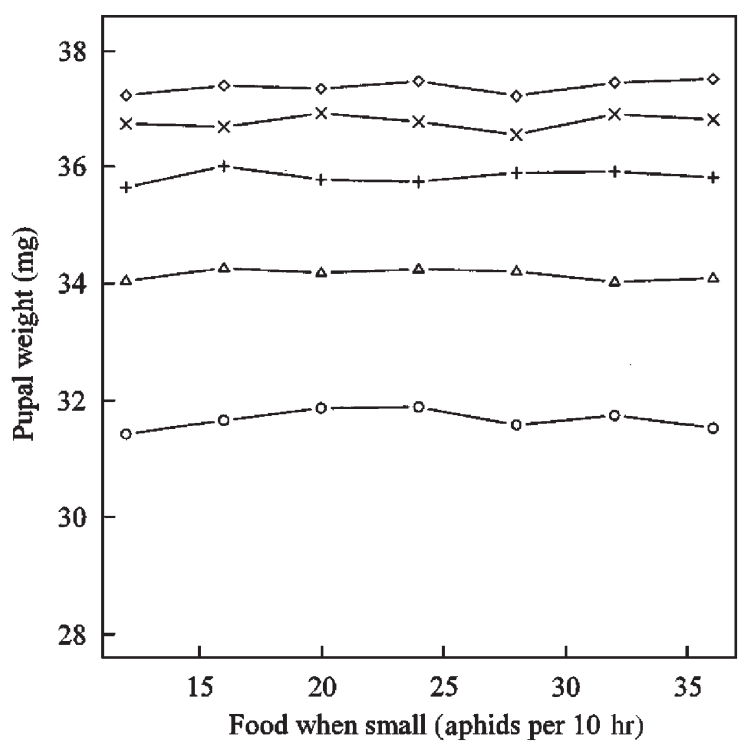

Figure 3. Reaction norms for pupal weight as a function of the average food availability when small $\left(\varphi_{\text {small }}\right)$, for different food availabilities when large $\left(\varphi_{\text {large }}\right)$. All combinations of $\varphi$ were run with random food schedules. Standard errors of the means are omitted for clarity, and range from 0.05 to $0.18 \mathrm{mg}$. Food when large (aphids per $10 \mathrm{hr}$ ): (०) 16; ( $\Delta)$ 20; (+) 24; (×) $28 ;(\diamond) 32$.

interested in the life-history consequences of shortterm variation in food availability, rather than the evolution of learning per se.

\section{Results}

A plot of development time or weight at pupation against $\varphi_{\text {small }}$ for different values of $\varphi_{\text {large }}$ is a "reaction norm surface" (Figs 3 and 4), because each larva experiences both values during its life. Weight at pupation is relatively insensitive to $\varphi_{\text {small }}$, and positively related to $\varphi_{\text {large }}$ (Figure 3 ). $\varphi_{\text {small }}$ only affects weight at pupation when reduced to the lowest levels, and the change is small relative to the effect of $\varphi_{\text {large }}$. Increasing $\varphi_{\text {large }}$ has a bigger impact on weight at pupation when $\varphi_{\text {large }}$ is low than when $\varphi_{\text {large }}$ is high. This is a result of the asymptote in the fitness function (Figure 1); small changes in weight at pupation have little effect on fitness when larvae are very large. The experience of a larva when it is small influences the time to pupation; a small larva compensates for low $\varphi_{\text {small }}$ by extending its development (Figure 4). The value of $\varphi_{\text {large }}$ has little effect on age at pupation. 


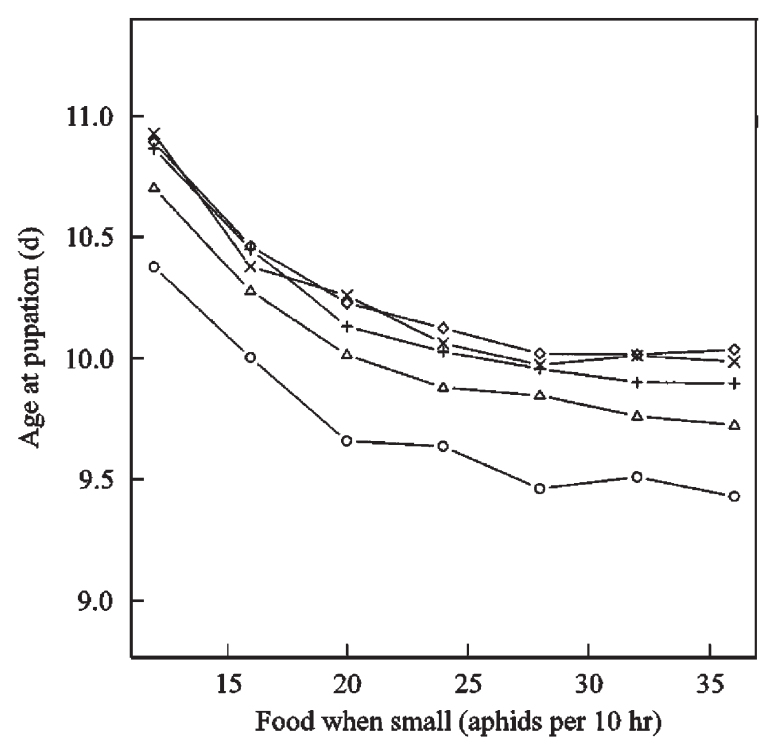

Figure 4. Reaction norms for developmental time as a function of the average food availability when small $\left(\varphi_{\text {large }}\right)$. All combinations of $\varphi$ were run with random food schedules. Standard errors of the means are omitted for clarity, and range from 0.02 to $0.06 \mathrm{~d}$. Food when large (aphids per $10 \mathrm{hr}$ ): (०) 16; $(\Delta) 20 ;(+)$ $24 ;(\times) 28 ;(\diamond) 32$.

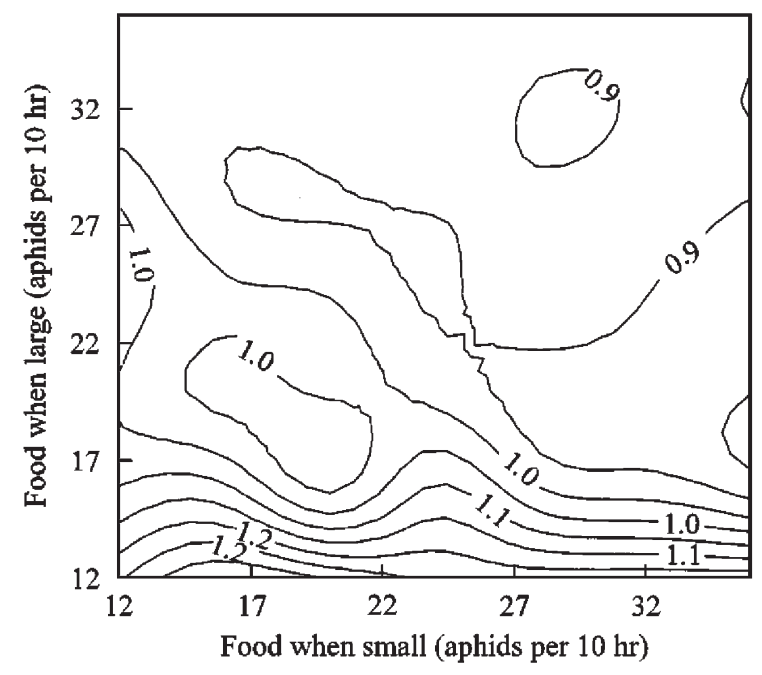

Figure 5. Performance of memory-using syrphids relative to syrphids assuming that food availability is a constant 24 aphids per $10 \mathrm{hr}$. Values above 1 indicate that estimating food availability with $\gamma=0.5$ provides a higher fitness return in that environment than by assuming that average food availability is constant.

The learning strategy performs better than a fixed estimate when food availability is less than the value of the fixed estimate (Figure 5). The learning strategy is best at responding to a decrease in food availabil-
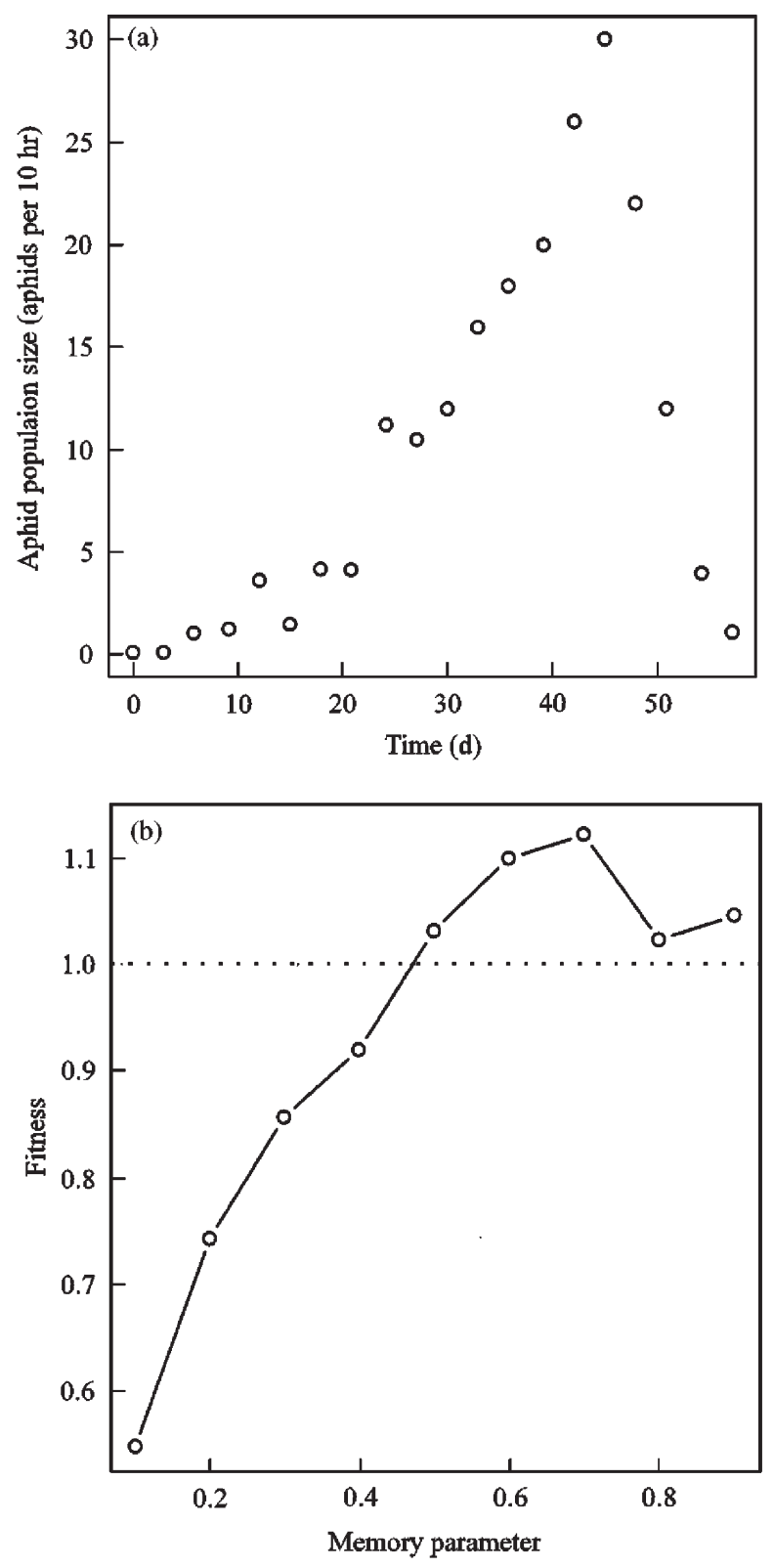

Figure 6. (a) Aphid population trajectory for one season from empirical data in Tenhumberg (1992). (b) Relative fitness of memory using syphids to syrphids using a fixed estimate of 24 aphids per $10 \mathrm{hr}$ as a function of the decay parameter $\gamma$ when aphid abundance varies as in (a).

ity late in development (i.e. $\varphi_{\text {large }}<\varphi_{\text {small }}$ ). When food availability is equal to or greater than the fixed estimate (24 aphids per $10 \mathrm{hr}$ ), the fixed estimate strategy is better. However, the learning strategy is never more than $10 \%$ worse than the fixed strategy, compared with up to $30 \%$ improvement over the fixed strategy when food availability is low.

The relative performance of the learning rule depends on both the degree of variation in food avail- 


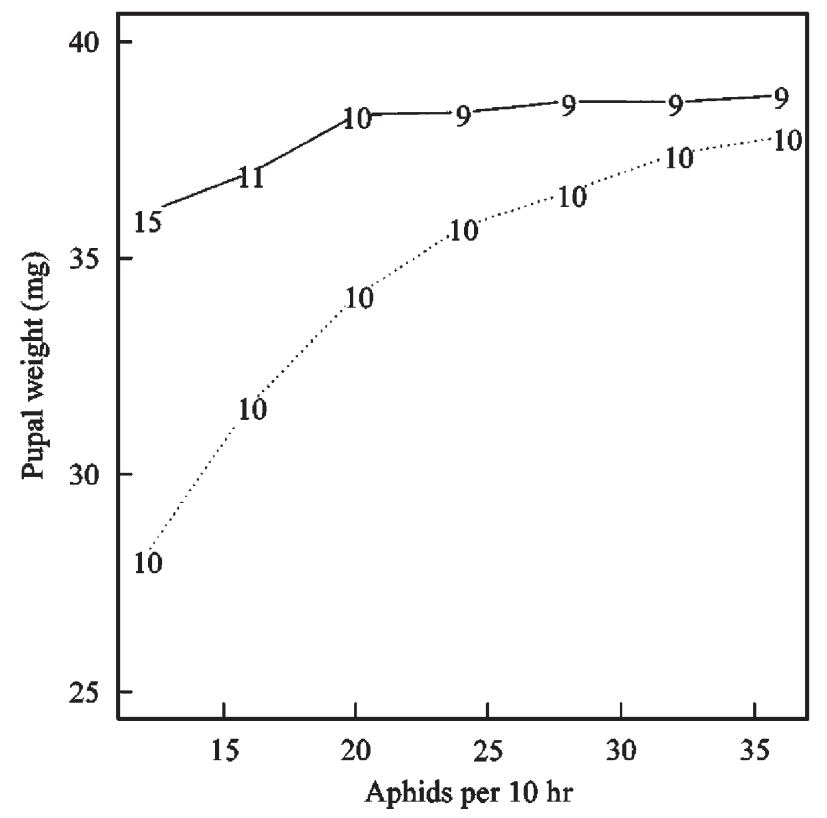

Figure 7. Reaction norms for pupal weight as a function of $\varphi$ for constant (solid line) and random (dotted line) food schedules. $\varphi$ did not vary during larval development, i.e. $\varphi_{\text {small }}=$ $\varphi_{\text {large }}$ always. The numbers denote the developmental time in days, rounded off.

ability, the initial estimate $m_{0}$, and the memory decay parameter $\gamma$. So far, we only changed food availability $\varphi$ at one point in the season; real aphid population trajectories are more complex (Figure 6a). In this more realistic environment, the learning rule performs up to $10 \%$ better than a fixed estimate $\left(m_{0}=24\right.$ aphids per $10 \mathrm{hr}$ ) depending on the value of $\gamma$ (Figure $6 b$ ). The "optimal" value of $\gamma$ is $\approx 0.7$.

\section{Effect of Stochastic Variation of Food Availability}

In the previous section, all larvae experienced randomly varying food supplies. We examine the effects of random vs. constant food schedules by plotting a reaction norm for pupal weight against $\varphi$ for both types of food schedule. We performed two sets of forward Monte Carlo simulations - one set with a constant food schedule and one with a random food schedule. Both sets of simulations use a single decision matrix from the SDP. In contrast to the previous section, we concentrate on the effects of the variance of food availability by keeping $\varphi$ constant within a generation.
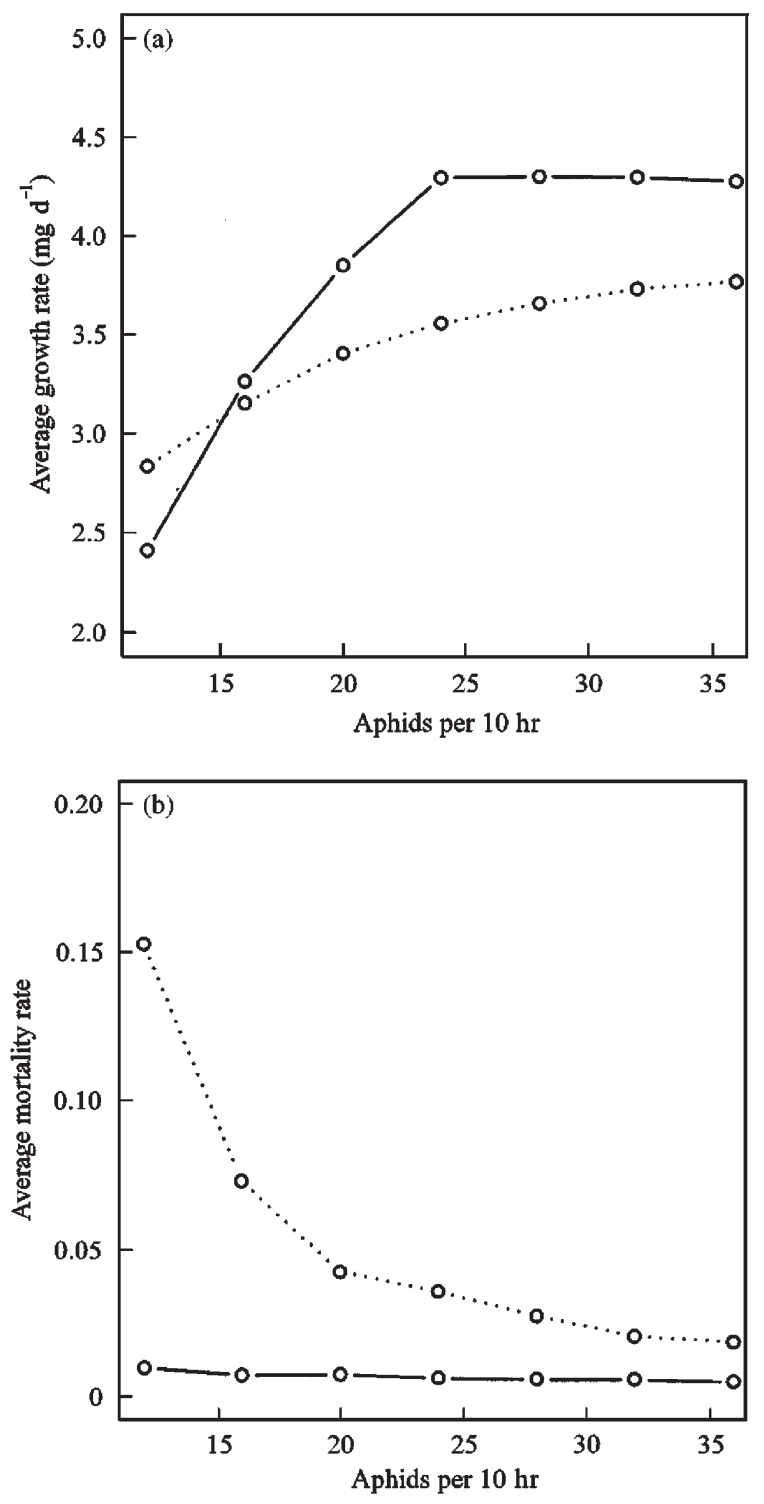

Figure 8. (a) Growth and (b) mortality rates as a function of food availability. Average growth rate is calculated as the pupal weight divided by age in days. Average mortality rate is calculated using $\mathrm{e}^{-\mu t}=$ the proportion of individuals surviving to pupation, where $\mu$ is the average mortality rate and $t$ is the average age at pupation. Constant food schedules are shown with solid lines, random food schedules are shown with dotted lines.

\section{Results}

Whether food availability is constant or random, larvae respond to low food availability by pupating smaller and later (Figure 7). Larvae on constant food schedules readily extend development to compensate for reduced growth rates, and therefore do not lose as much in terms of size. Random food schedule lar- 
Table 2. The responses to age and size of maturity to reductions in resource availability or growth rate, as a function of the relationship between mortality $(d)$ and growth rate $(g)$. "- "represents a decrease in size or age, " + " represents an increase, and " 0 " denotes no change. Only models of determinate growth that calculated the effect of changes in growth rate or resource availability are included. The effect of reductions in resource availability is related to the sign of $\partial d / \partial g$

\begin{tabular}{lrrrl}
\hline Source & $\partial d / \partial g$ & Size & Age & Other assumptions \\
\hline Charnov (1989) & $>0$ & 0 & + & \\
Ludwig \& Rowe (1990)* & 0 & - & - & \\
Rowe \& Ludwig (1991) $\dagger$ & 0 & - & $\approx 0$ & \\
Kindlmann \& Dixon (1992) & 0 & - & + & \\
Berrigan \& Koella (1994) & $>0$ & + & + & Growth rate large \\
& 0 & - & - & Growth rate small \\
This paper & $<0$ & - & + & Random food \\
& $<0$ & - & $\approx 0$ & Constant food \\
\hline
\end{tabular}

* These are models of ontogenetic niche shifts, rather than age and size at maturity. They are included in this table assuming that the niche shift corresponds to maturation, and the reduction in growth rate applies to the first habitat.

† This is the result for their model of mayfly emergence. Change in age at maturity is very small regardless of growth rate. At "large" growth rates (their parameter $r>0.09$ ), a 30\% decrease in growth rate produces a 30\% decrease in weight at emergence, but less than $2 \%$ increase in age at emergence.

vae do not extend development to the same degree, and consequently pupate at smaller sizes. The three highest food availabilities are essentially ad libitum, because increased food availability does not increase average growth rate on constant food schedules (Figure 8a). Maximum gut capacity limits growth at this point. Mortality from starvation increases with decreasing food availability on random food schedules, but not on constant food schedules (Figure 8b).

\section{Discussion}

In this paper we explored, for a specific species, the consequences of relaxing two common assumptions made in life-history models. First, we allowed foraging effort to depend on two internal states, weight and gut content, rather than assume that foraging effort was constant. The ability to vary foraging effort is increasingly recognized as an important contributor to variation in life-history strategies of a wide range of organisms (e.g. Ydenberg, 1994). Sec- ond, we allowed food availability to vary on small timescales, rather than assume that it was constant during the developmental period. This variation introduces a risk of starvation that is negatively correlated with growth rate, and that cannot be avoided by altering foraging behavior. The two most important results are that (1) small-scale stochastic variation in food availability affects life-history parameters, and (2) the timing of restrictions of average food supply is important.

Short-term stochastic fluctuations in food availability influence life-history parameters primarily by increasing the risk of mortality. When food availability is constant there is no risk of mortality from starvation. Random food schedules are different; even at moderate food supply there is a probability that an individual can starve to death. This introduces a negative relationship between growth rate and mortality. The adaptive response is to pupate at a smaller size at the same time. Stochastic variation in food supply is probably the norm under natural conditions for predators, rather than the exception. Negative correlations 
between growth rate and mortality have been observed in other insects in the field (Collins, 1980; Berrigan \& Koella, 1994). Unfortunately constant food availability is normally applied in experimental situations for logistical reasons (e.g. Ernesting et al., 1992), making tests of this prediction difficult.

The prediction that life-history traits such as age and size at maturity should be sensitive to risk even in the absence of fine-grained behavioral options is new, to the best of our knowledge. Previous theoretical and experimental work on risk sensitivity has examined behavioral decisions about where and how to forage (Krebs \& Kacelnik, 1991; Clark, 1994), given differences in the variance of foraging success between different options. This sort of approach assumes that individuals forage in a finegrained environment; various options are available within a single lifetime or in different foraging bouts. This is the scenario faced by the classic study organism in foraging behavior, the "small bird in winter" (Lima, 1986). Our model assumes that syrphids are in a coarse-grained environment. Individuals cannot choose different foraging options within their lifetime, they are stuck with what they get. We have shown that individuals in coarse-grained environments can be "risk averse" by shortening their development, or "risk prone" by extending their development. We return to this notion below, when discussing the response to changes in average food availability at different times.

The results of previous models have been largely driven by the direction of the assumed relationship between growth rate and mortality (Table 2). In our model, growth rate depends on the amount of time spent foraging, or foraging effort. Foraging effort affects mortality in two different ways. First, foragers are exposed to a low, constant predation risk that is independent of their internal states. Second, foraging gives individuals the opportunity to increase their gut content, decreasing the probability that they will starve to death. Whether or not mortality increases with foraging effort depends on the state of the individual. Individuals that are near starvation will probably decrease their overall risk of mortality by foraging, even though it exposes them to predation. Individuals that have full guts will increase their risk by foraging. Weight also modifies this relationship by increasing the energetic costs of foraging at large sizes. Large individuals are more likely to starve when foraging. Regardless of internal state, reductions in food availability increase mortality and decrease average growth rate. The negative relationship between growth rate and mortality is the result of realistic, specific assumptions about the way food intake is translated into growth and maintenance.

Given the importance of the sign of the relationship between mortality and growth rate, it is worthwhile to consider the various reasons given for the signs chosen by modelers. Abrams et al. (1996) and Abrams \& Rowe (1996) cite increased exposure to predators with increased foraging effort, or "other components of mortality" as the reason for a positive relationship. Ludwig \& Rowe (1990) assume that mortality decreases with size because larger individuals are better able to defend themselves. Stearns \& Koella (1986) also assumed that escape from predation at large sizes reduced juvenile mortality with increased growth rate, but they had an additional assumption that juvenile mortality increased with earlier maturation. Kindlmann \& Dixon (1992) produced a specific model for aphids and used empirical data to justify the absence of an effect of growth rate on mortality. Hernandez \& León (1995) and Rowe \& Ludwig (1991) assume no relationship, apparently for mathematical simplicity. Finally, some general models have analyzed the effects of all possible relationships (Perrin \& Rubin, 1990; Berrigan \& Koella, 1994). It is clear that if food consumption is at all stochastic, there will be a trade-off between starvation and predation (McNamara \& Houston, 1987b). In our model, the negative relationship between mortality rate and growth rate arises from the nature of physiological constraints of digestion and gut capacity. The importance of this cannot be overstated. State-dependent constraints are not difficult to incorporate in models of lifehistory evolution, and their inclusion grounds the model in reality. This approach is currently yielding significant dividends in modeling salmonid life histories (Mangel, 1994; Thorpe et al., 1998). Ernesting (1995) suggested physiological constraints as the solution to at least one "evolutionary puzzle" (Berrigan \& Charnov, 1994). 
Ludwig \& Rowe (1990) calculate the optimal time to switch between two habitats that differ in growth rate and mortality using deterministic dynamic programming, in contrast to the stochastic dynamic programming used here. They point out that a deterministic model is an adequate approximation even in the presence of stochastic variation in food availability if the number of opportunities to correct a deficit in energy balance is large. This effect is responsible for the insensitivity of Red Deer life histories to stochastic effects (Benton et al., 1995). Red deer are a long-lived, iteroparous species, and so "average over" stochastic fluctuations. In our model, the time to starvation decreases rapidly with decreasing food availability, and therefore a deterministic strategy is a poor approximation at low food availability, as demonstrated in our comparisons between memory using and fixed estimate strategies.

The timing of changes in average food availability also influences the optimal life-history strategy. Reductions in food availability, when large, have little influence on developmental time, and a great influence on weight. Again, changes in average food availability within a season are common for many organisms with life histories similar to those of syrphids (Goater, 1994; Leips \& Travis, 1994). Leips \& Travis (1994) experimentally confirmed that the effect of changes in food availability on the timing of metamorphosis depended on when changes occurred within the season for two frog species. They attributed this effect to a "window of opportunity" for changing the developmental program. Individuals who experienced reduced food availability sufficiently early could alter the timing of metamorphosis; changes that occurred later simply reduced their size at metamorphosis. Windows of opportunity for changing developmental trajectories have also been described for salmonids (Thorpe et al., 1998). Our model suggests that such a window could be adaptive in the presence of negative relationships between mortality and growth rate.

The different responses of large and small larvae to low average food availability, and consequently, reduced growth rates, is an example of Clark's (1994) asset protection principle. In simple terms, the larger the reproductive asset an individual has, the lower the risk of mortality the individual should accept to increase the asset. In this case, the asset being protected is the weight (potential fitness) already gained. Small larvae with low growth rates, and a high probability of starving have little to lose; they take the risk of extending development. Large larvae which experience a reduced growth rate have already gained some potential fitness; therefore they protect their assets from mortality by starvation and pupate earlier at smaller sizes. In addition, large larvae are more likely to starve to death at a particular mean food availability because their maintenance costs are higher. This is entirely consistent with the larger body of literature on risk sensitivity in general (Real \& Caraco, 1986; Krebs \& Kacelnik, 1991). In fact, the asset protection principle is a generalization of the conditions under which risk sensitivity will occur.

The timing of changes in average food availability is important in our model for two reasons. First, growth rates and foraging expenditures are dependent on size. Second, conditions are not constant within a season because the probability that the season terminates increases with time (conditional end-of-season). Abrams (1991) explored the effect of changes in average food availability within a developmental season on optimal foraging effort. His model was state-independent, and so the timing of changes within the season could be ignored; generally, foraging effort increased during periods of increased food availability. In our model, because growth and mortality rates are dependent on size, changes in average food availability early in the season, when larvae are small, have a different effect than changes late in the season. The effect is exacerbated because individuals developing late in the season face an additional mortality risk due to the probability that the aphid population collapses before they complete development.

In our model, the performance of learning individuals depends on the interaction between the decay parameter $\gamma$ and the degree of variation in the environment (e.g. Figure 6b). This strong effect of the decay parameter is in sharp contrast to a similar model tested by Mangel (1990). There, the decay parameter had a small and inconsistent effect on the relative performance of the learning strategy, although there did appear to be an internal optimum value that 
maximized performance. The differences between Mangel's model and our model may be instructive of the conditions under which learning is valuable. In Mangel's model, the learning strategy is discriminating between patches of different quality, i.e. a fine-grained behavioral option. In our model, the learning strategy is estimating the risk of extinction in a coarse-grained environment. It could be that learning is generally more advantageous in coarse-grained environments.

In this paper, we described an SDP model that generates a solution to the trade-off between increasing fitness and the risk of mortality during the juvenile period for aphidophagous syrphids. The take-home message is that short-term changes in food availability matter, because (1) variance in food availability introduces a negative relationship between growth rate and mortality, and (2) the timing of changes influences the effect. Food availability, and consequently, growth rates, are rarely constant during the developmental period of predatory organisms like syrphids. Many other organisms also face short-term variability and size-dependent costs (Lima, 1986). The results of this model demonstrate a need for future life-history models and experiments to address variation in phenotypic traits as risk-sensitive responses to variation in environmental variables within the developmental period.

Acknowledgments - Early versions of this manuscript benefited from constructive comments by the Roitberg Lab Group at Simon Fraser University, in particular, Mike Robinson, Ian Robertson, and Rob McGregor. Colin Clark, Derek Roff, Hugh Possingham, members of the PHLEgM discussion group at the University of Adelaide, and three anonymous reviewers for Journal of Theoretical Biology also provided helpful comment. This work was supported by a Postdoctoral Research Award from the DFG to BT, by an NSERC PGS A award to AJT, and by an NSERC operating grant to BDR.

\section{References}

Abrams, P. A. (1991). Life history and the relationship between food availability and foraging effort. Ecology 72, 1242-1252.

Abrams, P. A., Leimar, O., Nylin, S., \& Wiklund, C. (1996). The effect on flexible growth rates on optimal sizes and development times in a seasonal environment. Am. Nat. 147, 381-395.

Abrams, P. A., \& Rowe, L. (1996). The effects of predation on the age and size of maturity of prey. Evolution 50, 1052-1061.

Alcock, J. (1989). Animal Behavior: An Evolutionary Approach. Sunderland, MA: Sinauer Associates.

Barkan, C. P. L. (1990). A field test or risk sensitive foraging in black-capped chickadees (Parus atricapillus). Ecology 71, 391-400.

Bastian, O. (1986). Schwebfliegen. Wittenberg, Lutherstadt: Brehm-Bücherei, A. Ziemsen Verlag.

Bell, W. J. (1991). Searching Behavior: The Behavioral Ecology of Finding Resources. New York: Chapman \& Hall.

Bellman, R. (1957). Dynamic Programming. Princeton: Princeton University Press.

Benton, T. G., Grant, A., \& Clutton-Brock, T. H. (1995). Does environmental stochasticity matter? Analysis of red deer life-histories on Rum. Evol. Ecol. 9, 559-574.

Berrigan, D., \& Charnov, E. (1994). Reaction norms for age and size at maturity in response to temperature: A puzzle for life historians. Oikos 70, 474-478.

Berrigan, D., \& Koella, J. C. (1994). The evolution of reaction norms: Simple models for age and size at maturity. J. Evol. Biol. 7, 549-566.

Bouskila, A., Robinson, M. E., Roitberg, B. D., \& Tenhumberg, B. (1998). Life-history decisions under predation risk-Importance of a game perspective. Evol. Ecol. 12, 701-715.

Buggle, V. (1994). Das suchverhalten der schwebfliegenlarvae Episyrphus balteatus Deg (Diptera: Syrphidae). University of Göttingen.

Bull, C. D., Metcalfe, N. B., \& Marc, M. (1996). Seasonal matching of foraging to anticipated energy requirements in anorexic juvenile salmon. Proc. Roy. Soc. Lond. Ser. B 263, 13-18.

Cartar, R. V. (1991). A test of risk-sensitive foraging in wild bumble bees. Ecology 72, 888-895.

Charlesworth, B. (1994). Evolution in Age-Structured Populations. Cambridge: Cambridge University Press.

Charnov, E. L. (1989). Natural selection on age of maturity in shrimp. Evol. Ecol. 3, 236-239.

Clark, C. W. (1994). Antipredator behavior and the assetprotection principle. Behav. Ecol. 5, 159-170.

Cole, L. C. (1954). The population consequences of life history phenomena. Q. Rev. Biol. 29, 103-137.

Colegrave, N. (1993). Does larval competition affect fecundity independently of its effect on adult weight? Ecol. Ent. 18, 275-277. 
Collins, N. S. (1980). Developmental responses to food limitation as indicators of environmental conditions for Ephydra cinerea Jones (Diptera). Ecology 61, 650-661.

Dingle, H. (1992). Food level reaction norms in size-selected milkweed bugs (Oncopeltus fasciatus). Ecol. Ent. 17, 121-126.

Ernesting, G. (1995). Ectotherms, time and temperature: Reaction norms for age and size at maturity. Oikos 72, 444-445.

Ernesting, G., Isaaks, J. A., \& Berg, M. P. (1992). Life cycle and food availability indices in Notiophilus biguttatus (Coleoptera, Carabidae). Ecol. Ent. 17, 33-42.

Ernesting, G., Zonneveld, C., Isaaks, J. A., \& Kroon, A. (1993). Size at maturity and patterns of growth and reproduction in an insect with indeterminate growth. Oikos 66, 17-26.

Gaudchau, M. (1982). Zur dauerzucht von Epistrophe balteata Deg (Diptera, Syrphidae). Anz. Schädlingsk. Pft. Umweltschutz 55, 38-39.

Goater, C. P. (1994). Growth and survival of postmetamorphic toads: Interactions among larval history, density, and parasitism. Ecology 75, 2264-2274.

Gutierrez, A. P., Baumgaertner, J. P., \& Hagen, K. S. (1981). A conceptual model for growth, development, and reproduction in the ladybird beetle, Hippodamia convergens (Coleoptera: Coccinellidae). Can. Ent. 113, 21-33.

Harder, L. D., \& Real, L. A. (1987). Why are bumble bees risk averse. Ecology 68, 1104-1108.

Heimpel, G. E., Rosenheim, J. A., \& Mangel, M. (1996). Egg limitation, host quality, and dynamic behavior by a parasitoid in the field. Ecology 77, 2410-2420.

Hernandez, M.-J., \& León, J. A. (1995). Evolutionary perturbations of optimal life histories. Evolut. Ecol. 9, 478-494.

Hinton, H. E. (1981). Biology of Insect Eggs. Oxford, England: Pergamon.

Houston, A. I., \& McNamara, J. M. (1992). Phenotypic plasticity as a state-dependent life-history decision. Evol. Ecol. 6, 243-253.

Kawecki, T. J., \& Stearns, S. C. (1993). The evolution of life histories in spatially heterogeneous environments: Optimal reaction norms revisited. Evolut. Ecol. 7, 155-174.

Kindlmann, P., \& Dixon, A. F. G. (1992). Optimum body size: Effects of food quality and temperature, when reproductive growth rate is restricted, with examples from aphids. J. Evol. Biol. 5, 677-690.

Kooijman, S. A. L. M. (1993) Dynamic Energy Budgets in Biological Systems. Cambridge, England: Cambridge University Press.

Kozlowski, J. (1992). Optimal allocation of resources to growth and reproduction: Implications for age and size at maturity. Trends Ecol. Evol. 7, 15-19.
Krebs, C. J. (1989). Ecological Methodology. Cambridge: Harper and Row.

Krebs, J. R., \& Kacelnik, A. (1991). Decision making. In: Behavioral Ecology: An Evolutionary Approach (Krebs, J. R., \& Davies, N. B., eds.). Oxford: Blackwell.

Leips, J., \& Travis, J. (1994). Metamorphic responses to changing food levels in two species of hylid frogs. Ecology $75,1345-1356$.

Li, C., Roitberg, B. D., \& Mackauer, M. (1993). Patch residence and parasitism of Aphelinus asychis: A simulation model. Ecol. Model. 69, 227-241.

Lima, S. L. (1986). Predation risk and unpredictable feeding conditions: Determinants of body mass in birds. Ecology $67,377-385$.

Ludwig, D., \& Rowe, L. (1990). Life-history strategies for energy gain and predator avoidance under time constraints. Am. Nat. 135, 686-707.

Mangel, M. (1990). Dynamic information in uncertain and changing Worlds J. theor. Biol. 146, 317-332.

Mangel, M. (1994). Climate change and salmonid life history variation. Deep-Sea Research II 41, 75-106.

Mangel, M., \& Clark, C. W. (1988). Dynamic Modeling in Behavioral Ecology. Princeton: Princeton University Press.

Mangel, M., \& Roitberg, B. D. (1989). Dynamic information and host acceptance by a tephritid fruit fly. Ecol. Ent. 14, 181-189.

Mangel, M., Rosenheim, J. A., \& Adler, F. R. (1994). Clutch size, offspring performance and intergenerational fitness. Behav. Ecol. 5, 412-417.

Maynard-Smith, J. (1982). Evolution and the Theory of Games. Cambridge: Cambridge University Press.

McNamara, J. M., \& Houston, A. I. (1985). Optimal foraging and learning. J. theor. Biol. 117, 231-249.

McNamara, J. M., \& Houston, A. I. (1987a). Memory and the efficient use of information. J. theor. Biol. 125, 385-395.

McNamara, J. M., \& Houston, A. I. (1987b). Starvation and predation as factors limiting population size. Ecology 68, 1515-1519.

Mylius, S. D., \& Diekmann, O. (1995). On evolutionarily stable life histories, optimization, and the need to be specific about density dependence. Oikos 74, 218-224.

Nonacs, P., Smith, P. E., \& Mangel, M. (1998). Modeling foraging in the northern anchovy (Engraulis mordax): Individual behavior can predict school dynamics and population biology. Can. J. Fisheries Aquatic Sci. 55, 1179-1188.

Ohnesorge, B., \& Viereck, A. (1983) Zur Befallsdichte-Abschätzung bei getreideblattläusen. Z. Pflanzenkrankheiten Pflanzenschutz 90, 213-219. 
Orians, G. H. (1981). Foraging behavior and the evolution of discriminatory abilities. In: Foraging Behavior: Ecological, Ethological, and Physiological Approaches (Kamil, A. C., \& Sargent, T. D., eds.), pp. 389-408. New York: Garland and STPM Press.

Perrin, N., \& Rubin, J. F. (1990). On dome-shaped norms of reaction for size-to-age at maturity in fishes. Funct. Ecol. $4,53-57$.

Real, L. A., \& Caraco, T. (1986). Risk and foraging in stochastic environments: Theory and evidence. Ann. Rev. Ecol. Syst. 17, 371-390.

Roff, D. (1983). Phenological adaptation in a seasonal environment: A theoretical perspective. In: Diapause and Life Cycle Strategies in Insects (Brown, V. K., \& Hodek, I., eds.), pp. 253-270. The Hague: Dr W. Junk Publishers.

Roff, D. A. (1992). The Evolution of Life Histories: Theory and Analysis. New York: Chapman \& Hall.

Rowe, L., \& Ludwig, D. (1991). Size and timing of metamorphosis in complex life cycles: Time constraints and variation. Ecology 72, 413-427.

Schmidt-Nielsen, K. (1984). Scaling, Why is Animal Size so Important? Cambridge, England: Cambridge University Press.

Speight, M. R. (1994). Reproductive capacity of the horse chestnut scale insect, Pulvinarian regalis Canard (Hom., Coccidae). J. appl. Ent. 118, 59-67.
Stearns, S. C. (1992). The Evolution of Life Histories. Oxford, England: Oxford University Press.

Stearns, S. C., \& Koella, J. C. (1986). The evolution of phenotypic plasticity in life-history traits: Predictions of reaction norms for age and size at maturity. Evolution 40, 893-913.

Tenhumberg, B. (1992). Untersuchungen zur populationsdynamik von syrphiden in winterweizenbeständen und quantifizierung ihrer bedeutung als antagonisten von getreideblattläuisen, Poehling, P.H.M. University of Göttingen.

Tenhumberg, B., \& Poehling, H. M. (1995). Syrphids as natural enemies of cereal aphids in Germany: Aspects of their biology and efficacy in different years and regions. Agric. Ecosyst. Environ. 52, 39-43.

Thornhill, R., \& Alcock, J. (1983). The Evolution of Insect Mating Systems. Cambridge, MA: Harvard University Press.

Thorpe, J. E., Mangel, M., Metcalfe, N. B., \& Huntingford, F. A. (1998). Modelling the proximate basis of salmonid life-history variation, with application to Atlantic salmon, Salmo salar L. Evol. Ecol. 12, 581-599.

Ydenberg, R. C. (1994). The behavioral ecology of provisioning in birds. Ecoscience 1, 1-14. 